\title{
Decreased Functional Capacity in Individuals with Chronic Non-Specific Low Back Pain: A Cross-Sectional Comparative Study
}

This article was published in the following Dove Press journal: Journal of Pain Research

\author{
Roongtiwa Vachalathiti (D) \\ Prasert Sakulsriprasert (iD) \\ Pathaimas Kingcha (iD ${ }^{2}$ \\ 'Division of Physical Therapy, Faculty of \\ Physical Therapy, Mahidol University, \\ Nakhon Pathom, Thailand; ${ }^{2}$ Physical \\ Therapy Center, Faculty of Physical \\ Therapy, Mahidol University, Bangkok, \\ Thailand
}

Purpose: This study aimed to compare functional capacity tests between individuals with and without chronic non-specific low back pain and to investigate the effects of demographic data on functional capacity tests.

Methods: Thirty individuals with chronic non-specific low back pain (CNSLBP) and thirty healthy individuals underwent three functional capacity tests comprising functional reach test (FRT), five-time sit to stand test (5 TSST), and two-minute step test (2 MST). CNSLBP were assessed in pain intensity using a visual analog scale (VAS) and disability level using the modified Oswestry disability questionnaire (MODQ) Thai version.

Results: The results found significant differences in five-time sit to stand and two-minute step tests between individuals with chronic non-specific low back pain and healthy individuals. The mean differences between healthy and CNSLBP for the 5 TSST were -3.24 seconds $(95 \% \mathrm{CI}=-4.47-2.02)$ and for the 2 MST they were 13.13 steps $(95 \%$ $\mathrm{CI}=2.62-23.64)$. Age significantly influenced the 5 TSST $(P=0.004)$ and 2 MST $(P=0.008)$, while gender $(P=0.028)$ and height $(P=0.002)$ affected the FRT.

Conclusion: Individuals with chronic non-specific low back pain had lower functional capacity assessed by five-time sit to stand and 2-minute step tests compared to healthy individuals, and the therapeutic programs were emphasized. With increasing age, the 5 TSST and 2 MST would both be declined.

Keywords: physical examination, five-time sit to stand, two-minute step, functional reach

\section{Introduction}

According to diagnostic triage of low back pain (LBP), non-specific LBP is the largest group representing approximately $90-95 \%$ of LBP patients compared to the others, namely radicular LBP and specific LBP. ${ }^{1}$ There is no clear clinical evidence for non-specific LBP to identify the pain-sensitive structures, ${ }^{2}$ but mostly related to mechanical causes. ${ }^{3}$ Regarding onset, acute LBP will develop to be chronic, if the symptoms persist for 12 weeks or longer. ${ }^{4}$ The definite diagnosis for chronic nonspecific low back pain (CNSLBP) is complicated and the management aims to reduce pain and disability. ${ }^{5}$ Therefore, CNSLBP is one of the most significant health problems. The impacts are about the limitation of functional capacity and associated disability, which is highest in working age groups worldwide. ${ }^{6}$

The assessments for functional capacity and disability in patients with CNSLBP can be done with physical performance tests ${ }^{7,11}$ and self-administered questionnaires, ${ }^{12}$ respectively. Pfingsten et $\mathrm{al}^{9}$ found the differences in ability to perform eight physical
Correspondence: Roongtiwa Vachalathiti Physical Therapy Center, Faculty of Physical Therapy, Mahidol University, Nakhon Pathom 73170, Thailand

Email roongtiwa.vac@mahidol.ac.th
Journal of Pain Research 2020:13 1979-1986 
performance tests such as stair climbing, prolonged flexion, stand-to-floor, fingertip-to-floor, lift test, sock test, sit-up test and pick-up test, between LBP patients and healthy controls. Stand-to-floor was the most discriminatory test whereas pick-up and lift test produced moderate results. Rudy et $\mathrm{al}^{10}$ also reported the significant difference between older individuals with and without CLBP regarding physical and psychosocial functions.

The underlying causes of CNSLBP are complex, however, it has been postulated that the weakness of core stabilizer muscles in individuals is evident, contributing to its fatigability, ${ }^{13}$ poor trunk control, and mobility. ${ }^{14,15}$ Therefore, the functional capacity tests should be thought about when considering the challenge of trunk static and dynamic control, yet in a timely manner to prevent the excessive fatigue.

Functional reach test has been used as a clinical measure of dynamic balance with core muscle control. ${ }^{16}$ Fivetime sit to stand and two-minute step are promising because these tests are relevant to the dynamic function of trunk and lower limb muscles similarly to everyday working activities. Those tests were also used to measure in older adults representing dynamic balance and aerobic endurance. $^{17,18}$

The objectives of this study were to compare the functional capacity in individuals with CNSLBP and healthy individuals, and to investigate the effects of demographic data on those functional capacity tests. We hypothesized that individuals with CNSLBP had a lower functional capacity compared to healthy individuals, and there were some demographic data influencing those functional capacity tests.

\section{Methods}

\section{Study Design, Setting, and Subjects}

This study was a comparative study design comparing functional capacity tests between healthy and individuals with chronic non-specific low back pain. Thirty individuals with CNSLBP were recruited from the Physical Therapy Center, Faculty of Physical Therapy, Mahidol University during a period of 9-month data collection. CNSLBP patients had mild-to-moderate pain intensity (1-3 cm for mild pain and $3.1-6 \mathrm{~cm}$ for moderate pain on visual analog scale) of at least 3-month duration without radicular pain.

For the healthy group, 30 individuals who were interested in the research study through public announcement were recruited. The healthy individuals had no history of pain or any symptoms at their lumbosacral region within at least 6 months prior to participation. Exclusion criteria for both groups were any neurological conditions, cardiovascular diseases, history of spinal or lower limbs surgery or fracture, pain at lower extremities, pregnancy, and on menstruation. Healthy and CNSLBP received detailed information about the study and signed an informed consent form. This study was conducted in accordance with the Declaration of Helsinki and was approved by the Ethics Committee of the Mahidol University Central Institutional Review Board (MU-CIRB), no.2017/ 155.2808 .

Sample size calculation using a sample size calculator program, statulator.com, based on the data of five-time sit to stand from our pilot study. The confidence interval was set at $95 \%$, alpha level $5 \%$, power $80 \%$, mean difference 1.889 , and standard deviation 2.300 , then the calculated sample size of 24 subjects per group was needed to see the difference between groups. We also recruited $20 \%$ more in order to cover all possible missing values might happen. Therefore, 30 subjects per group, 60 in total, were recruited.

\section{Measurements}

\section{Pain Intensity}

Individuals with CNSLBP were assessed for pain intensity with a 10-centimeter horizontal visual analog scale (VAS) where the left side indicated "no pain" and the right side the "worst pain imaginable". The individuals with CNSLBP reported their pain intensity on worst movement or activity on the tested day by marking on the VAS.

\section{Disability Level}

Individuals with CNSLBP were assessed using the modified Oswestry Disability Questionnaire (MODQ) Thai version. $^{12}$ The total score of MODQ, Thai version, has been used by summarizing from 10 items; pain intensity, personal care, lifting, walking, sitting, standing, sleeping, social life, traveling, employment/home making, which is categorized into six levels of each item starting from 0 (no disability) to 5 (highest disability) and multiplied by 2 to gain a percentage of disability level. This can imply how pain affects various activities of daily living. The higher percentage represented a greater level of disability defined as follows: 0-20 minimal disability, 21-40 moderate 
disability, 41-60 severe disability, 61-80 crippled, and 81-100 bed bound or symptom magnifier.

\section{Physical Activity Level}

Physical activity level was measured with the Thai physical activity guideline (TPAG) ${ }^{19,20}$ describing level zero, most sedentary, to level five, most physically active. Those levels were derived from the calculation of energy expenditure based on the total time of physical activity during the last 7 days. The brief explanation is as follows; Level 0 : had no moderate-vigorous physical activity, Level 1 : had moderate intensity activity $\leq 150$ minutes/week or vigorous intensity activity $<75$ minutes/week. Level 2 : had moderate intensity activity $\geq 150$ minutes/week or vigorous intensity activity $\geq 75$ minutes/week. Level 3 : had moderate intensity activity $\geq 300$ minutes/week or vigorous intensity activity $\geq 150$ minutes/week. Level 4 : had moderate intensity activity $\geq 450$ minutes/week or vigorous intensity activity $\geq 225$ minutes/week. Level 5 : had moderate intensity activity $\geq 600$ minutes/week or vigorous intensity activity $\geq 300$ minutes/week.

\section{Functional Capacity Tests}

All subjects had to perform three functional capacity tests: functional reach, five-time sit to stand, and two-minute step, respectively. During the tests, all subjects wore comfortable clothes and canvas shoes for these tests. They were explained the test protocols and observed demonstration, with a question-and-answer session provided if needed.

Using the functional reach test (FRT), the researcher adhered a ruler to the wall at the subject's shoulder-height level and marked a shoulder-width feet placement sign on the floor. For starting position, the subjects stood sideways next to the wall without leaning against the wall, and flexed both shoulders to 90 degrees with elbows straight, hands fisting and the head of the 3rd metacarpal bone on the ruler was recorded. They were asked to reach forward with arms straight keeping at shoulder level as far as possible without stepping. ${ }^{16,21}$ They performed three trials, the farthest reach value was used. Figure1A and $\mathrm{B}$ demonstrate the starting position and final position of FRT.

The five-time sit to stand test (5 TSST) involved a chair that was positioned against the wall to secure the test location. For the starting position, the subjects sat in the middle of the chair, back straight without support, feet flat on the floor, and both arms were folded together across

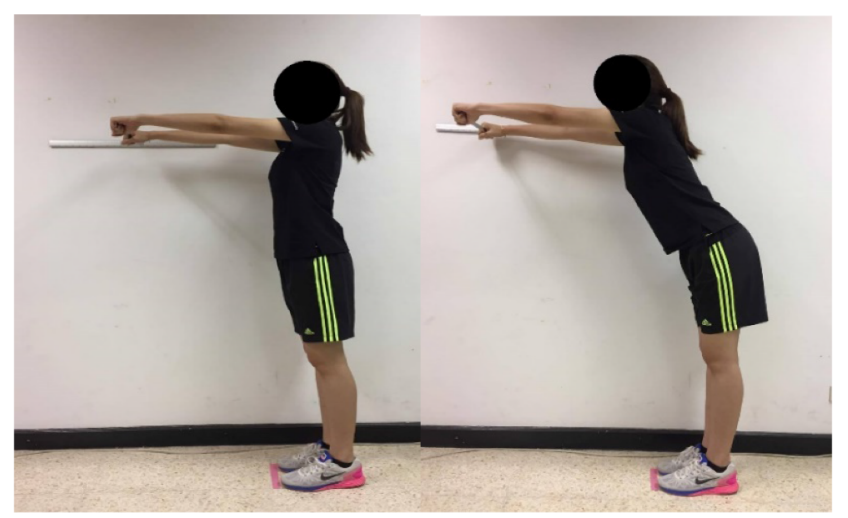

A

B

Figure I (A) Starting position of FRT, (B) Final position of RFT.

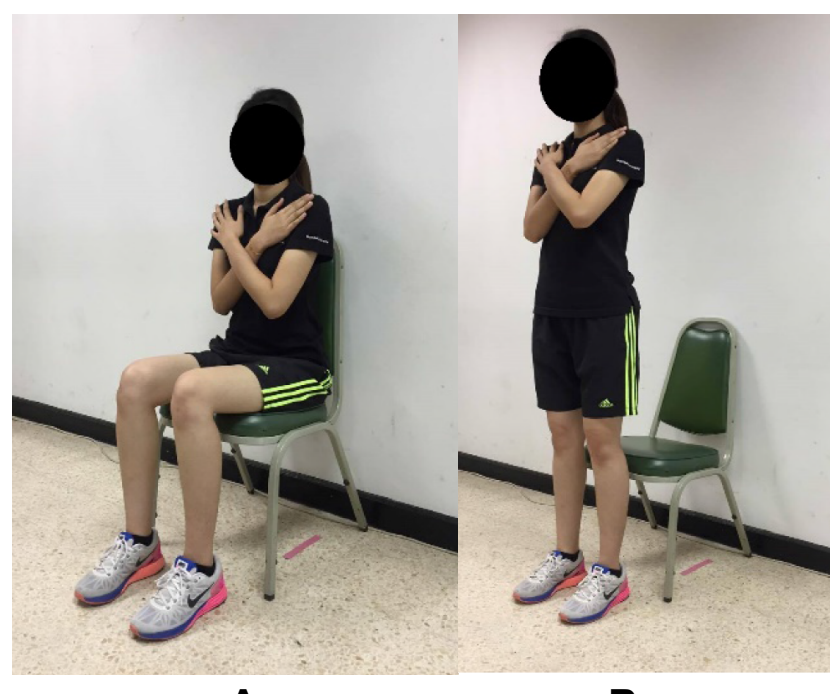

A

B

Figure 2 (A) Starting position of 5 TSST, (B) Final position of 5 TSST.

the chest (Figure 2A). They were then asked to rise to full stand and return to sitting position as fast as possible five times continuously (Figure 2B). They performed three trials, the shortest time spent to complete the five times was used. ${ }^{17}$

For the two-minute step test (2 MST), the researcher measured the stepping height of each subject, which was equal to the mid-thigh level, halfway between the iliac crest and patella, and marked that level on the wall (Figure 3A). The starting position was standing, the subject was then instructed to step by alternately moving the knee up to the marked level, beginning with the right knee and continuing to step for 2 minutes. The researcher counted the number of times the right knee successfully reached the marked level (Figure 3B). The subject was 


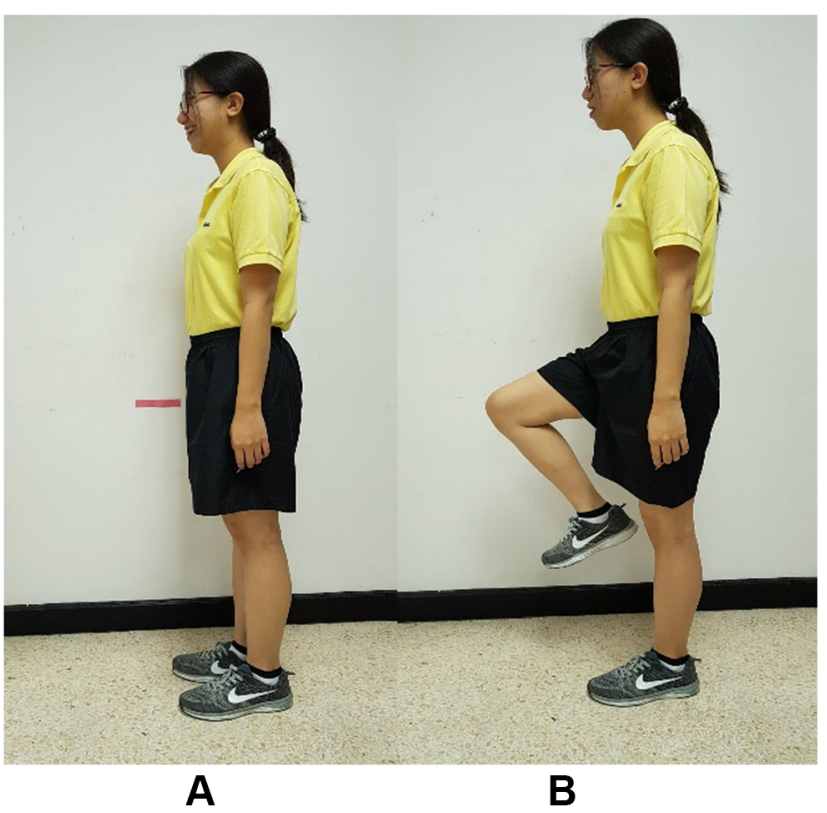

Figure 3 (A) Starting position of 2 MST, (B) Final position of 2 MST.

allowed to place one hand on a table for balance assistance if needed. ${ }^{17}$ They performed this test only once. However, before data collection, the researcher allowed the subject a short practice.

The rest interval was 2 minutes provided to reduce fatigue between each test. The researcher asked all subjects every time before starting the next tests to reassure that all subjects had no carry-over symptoms. After all tests, the subjects slowly walked for a few minutes to cool down.

\section{Statistical Analysis}

The demographic data were presented as mean \pm standard deviation, or number and percentage of the subjects. Chisquare test and independent $t$-test were used to compare demographic data in both groups. Shapiro-Wilk test was used to test the normal distribution of the data. As a comparison of functional capacity tests, the independent $t$-test was used for functional reach since the data were normally distributed, while the Mann-Whitney $U$-test was used for the five times sit to stand and two-minute step because of non-normal distribution. For the analyses of the demographic data on their influences to all functional capacity tests, a multiple linear regression, stepwise method, was used. Statistical analyses were done with SPSS program version 23 (IBM Corp., Armonk, NY), the statistical significance was set at a $P$-value less than 0.05 .

\section{Results}

The demographic data of both groups were similar in gender, age, weight, height, and BMI. However, the significant differences were found in working task and physical activity level between individuals with CNSLBP and healthy individuals. The individuals with CNSLBP had mild-to-moderate pain intensity and minimal disability level. Nearly $50 \%$ of healthy individuals had household working, while $56.7 \%$ of individuals with CNSLBP had prolonged sitting tasks. The physical activity domain demonstrated a higher level of physical activity in healthy individuals, as shown in Table 1.

The comparison of functional capacity tests between the individuals with CNSLBP and healthy individuals showed significant differences in five-time sit to stand and two-minute step. The mean differences between groups and $95 \%$ confidence intervals are also presented in Table 2.

For the effects of demographic data, it was found that age significantly influenced the five-time sit to stand $(P=0.004)$ and two-minute step test $(P=0.008)$, while gen$\operatorname{der}(P=0.028)$ and height $(P=0.002)$ affected on functional reach, as shown in Table 3.

\section{Discussion}

The first objective of this study was to compare the functional capacity between the individuals with CNSLBP and healthy individuals with three functional capacity tests. We found that the five-time sit to stand and two-minute step tests were significantly worsening in individuals with CNSLBP compared to healthy individuals. This finding corresponds to previous studies done with functional capacity tests or physical performance tests. ${ }^{7,9,10}$ The lower level of functional capacity in individuals with CNSLBP found in this study might be due to poor trunk motor control as shown by longer time spent in the five-time sit to stand and fewer steps counted in the two-minute step tests. Even though the rest interval provided between tests and the reassurance questions asked to every subject have been done as a standardized method, in this study.

Interestingly, the averaged value from two-minute step in individuals with CNSLBP in this study was 82.37 , close to older people aged 80-89 years showing an averaged value of 83.5. ${ }^{17}$ This result might give us the awareness of worsening of dynamic control and aerobic endurance in individuals with CNSLBP. Smeets et $\mathrm{al}^{22}$ also found a significant lower level of aerobic fitness in LBP patients 
Table I Demographic Data of the Participants

\begin{tabular}{|c|c|c|c|}
\hline Demographic Data & $\begin{array}{l}\text { Healthy } \\
(\mathrm{N}=30)\end{array}$ & $\begin{array}{l}\text { CNSLBP } \\
(\mathbf{N}=\mathbf{3 0})\end{array}$ & $P$-value \\
\hline \multicolumn{4}{|l|}{ Gender } \\
\hline Female & $25(83.3 \%)$ & 21 (70\%) & 0.222 \\
\hline Male & $5(16.7 \%)$ & $9(30 \%)$ & \\
\hline \multicolumn{4}{|l|}{ Age (years) } \\
\hline Mean \pm SD & $40.46 \pm 8.66$ & $43.500 \pm 8.53$ & 0.177 \\
\hline Range & $30-58$ & $32-60$ & \\
\hline \multicolumn{4}{|l|}{ Weight (kg) } \\
\hline Mean \pm SD & $58.46 \pm 9.08$ & $60.73 \pm 11.67$ & 0.405 \\
\hline Range & $44.00-75.00$ & $43.00-88.00$ & \\
\hline \multicolumn{4}{|l|}{ Height (cm) } \\
\hline Mean \pm SD & $159.26 \pm 8.74$ & $162.56 \pm 8.38$ & 0.141 \\
\hline Range & $\mid 46.00-180.00$ & $148.00-183.00$ & \\
\hline \multicolumn{4}{|l|}{ BMI $\left(\mathrm{kg} / \mathrm{m}^{2}\right)$} \\
\hline Mean $\pm S D$ & $23.09 \pm 3.45$ & $22.91 \pm 3.36$ & 0.843 \\
\hline Range & $17.60-31.08$ & $16.20-30.40$ & \\
\hline Underweight & $2(6.7 \%)$ & $2(6.7 \%)$ & \\
\hline Normal & $12(40 \%)$ & 15 (50\%) & \\
\hline Overweight & $5(16.7 \%)$ & $4(13.3 \%)$ & \\
\hline Obesity & II (36.7\%) & $9(30 \%)$ & \\
\hline \multicolumn{4}{|l|}{ Working task } \\
\hline Prolonged sitting & II (36.7\%) & 17 (56.7\%) & $0.003 * *$ \\
\hline Prolonged standing & $4(13.3 \%)$ & $10(33.3 \%)$ & \\
\hline $\begin{array}{l}\text { Other working, eg, } \\
\text { household working } \\
\text { or working with } \\
\text { changing positions }\end{array}$ & I5 (50\%) & $3(10.0 \%)$ & \\
\hline \multicolumn{4}{|l|}{ Physical activity level } \\
\hline 0 & $0(0 \%)$ & I (3.3\%) & $0.008 * *$ \\
\hline I & $3(10.0 \%)$ & II (36.7\%) & \\
\hline 2 & 7 (23.3\%) & $0(0 \%)$ & \\
\hline 3 & $3(10.0 \%)$ & 7 (23.3\%) & \\
\hline 4 & $6(20.0 \%)$ & $3(10.0 \%)$ & \\
\hline 5 & II (36.7\%) & $8(26.7 \%)$ & \\
\hline \multicolumn{4}{|l|}{ Pain intensity (VAS) } \\
\hline Mean \pm SD & - & $3.12 \pm 1.43$ & - \\
\hline Range & & $1.20-6.00$ & \\
\hline \multicolumn{4}{|l|}{ Disability level (\%) } \\
\hline Mean $\pm S D$ & - & $13.50 \pm 10.30$ & - \\
\hline Range & & $0-42$ & \\
\hline \multicolumn{4}{|l|}{$\begin{array}{l}\text { Pain duration } \\
\text { (months) }\end{array}$} \\
\hline Mean \pm SD & - & $33.7 \pm 35.14$ & - \\
\hline Range & & $3-120$ & \\
\hline
\end{tabular}

Notes: $P$-values were from chi-square, except age, weight, height, and BMI, which were from independent $t$-test. ** Denotes significant difference at $P<0.01$.

Abbreviations: CNSLBP, chronic non-specific low back pain; BMI, body mass index; VAS, visual analog scale. compared with healthy controls. This finding might reflect the functional capacity impairment in individuals with CNSLBP, which might be due to chronicallycompromised fibrosed connective tissue and muscle that leads to pain and movement restriction in CLBP. ${ }^{23}$ The appropriate interventions should be considered emphasizing the restoration of functional capacity.

In terms of the assessment methods, we encouraged the use of five-time sit to stand and two-minute step for clinical assessment tools since they can differentiate the individuals with CNSLBP from healthy individuals. Also, five-time sit to stand has been proved to be responsive for overtime measurements in chronic LBP patients. ${ }^{24}$ Time spent for the two tests is about 5 minutes including a 2-minute rest interval between that can be feasible clinically. However, functional reach was not different between two groups. Rudy et $\mathrm{al}^{10}$ found the difference in functional reach between older adults with and without chronic LBP. The indifferent result in this study can be surmised as that this test might not be challenging to the capacity of trunk muscles in individuals with CNSLBP of younger age, in contrast to older adults. ${ }^{10}$ However, the pattern of reach could be different among individuals, which this study did not investigate, considered as a limitation of this study. Future studies can investigate biomechanical parameters such as trunk and leg angles and angular velocity between the individuals with and without CNSLBP performing of functional reach to deepen the understanding of compensatory patterns, if present, caused by CNSLBP.

Most of the healthy individuals had a higher physical activity level and less in a prolonged sitting working task, while the individuals with CNSLBP had a significantly lower physical activity level and was engaged in prolonged sitting working tasks. These results correspond to the study done by Yiengprugsawan et al, ${ }^{25}$ who also found a reduction of physical activity in chronic LBP patients. However, other demographic data regarding gender, age, weight, height, and BMI showed no significant difference between the two groups. Although the individuals with CNSLBP in this study had mild-to-moderate pain intensity and minimal disability level, their test results were significantly lower. This results might be due to the contributing factors of physical capacity such as muscle strength, cardiovascular capacity, ${ }^{26}$, ${ }^{27}$ fear of movement, ${ }^{28,29}$ and pain during movement. ${ }^{30}$ This study therefore suggests that future studies can investigate the causal effects of those factors on functional capacity in individuals with CNSLBP. 
Table 2 Functional Capacity Tests Between Healthy and CNSLBP Groups

\begin{tabular}{|l|l|l|l|l|l|}
\hline $\begin{array}{l}\text { Functional Capacity } \\
\text { Tests }\end{array}$ & $\begin{array}{l}\text { Healthy } \\
\mathbf{( N = 3 0 )}\end{array}$ & $\begin{array}{l}\text { CNSLBP } \\
\mathbf{( N = 3 0 )}\end{array}$ & $\begin{array}{l}\text { Mean } \\
\text { Difference }\end{array}$ & $\begin{array}{l}\text { 95\% Confidence Interval of the } \\
\text { Difference }\end{array}$ & P-value \\
\hline $\begin{array}{l}\text { FRT }(\mathrm{cm}) \\
\begin{array}{l}\text { Mean } \pm S D \\
\text { Range }\end{array}\end{array}$ & $\begin{array}{l}35.75 \pm 5.75 \\
21.50-45.00\end{array}$ & $\begin{array}{l}33.86 \pm 6.66 \\
20.00-49.00\end{array}$ & 1.89 & $-1.32-5.10$ & 0.245 \\
\hline $\begin{array}{l}\mathbf{5} \text { TSST (sec) } \\
\begin{array}{l}\text { Mean } \pm S D \\
\text { Range }\end{array}\end{array}$ & $\begin{array}{l}8.08 \pm 1.59 \\
5.39-12.47\end{array}$ & $\begin{array}{l}11.33 \pm 2.92 \\
6.97-16.46\end{array}$ & -3.24 & $-4.47--2.02$ & $0.001 * *$ \\
\hline $\begin{array}{l}\mathbf{2} \text { MST (steps) } \\
\text { Mean } \pm S D \\
\text { Range }\end{array}$ & $\begin{array}{l}95.50 \pm 16.41 \\
45-129\end{array}$ & $\begin{array}{l}82.37 \pm 23.52 \\
26-121\end{array}$ & 13.13 & $2.62-23.64$ & $0.025^{*}$ \\
\hline
\end{tabular}

Notes: * Denotes significant difference at $P<0.05$, ** Denotes significant difference at $P<0.01$.

Abbreviations: CNSLBP, chronic non-specific low back pain; SD, standard deviation; FRT, functional reach test; 5 TSST, five-time sit to stand test; 2 MST, two-minute step test.

Table 3 Multiple Linear Regression Investigating the Effects of Demographic Data on Each Functional Capacity Test in All Participants $(\mathrm{N}=60)$

\begin{tabular}{|c|c|c|c|c|c|}
\hline \multirow[t]{2}{*}{ Variables } & \multicolumn{2}{|c|}{ Unstandardized Coefficients } & \multirow[t]{2}{*}{ Standardized Coefficients $\beta$} & \multirow[t]{2}{*}{$\mathbf{t}$} & \multirow[t]{2}{*}{ P-value } \\
\hline & B & SE & & & \\
\hline \multicolumn{6}{|l|}{ FRT (cm) } \\
\hline Constant & $-|6.27|$ & 16.486 & - & -0.987 & 0.328 \\
\hline Gender & -5.133 & 2.278 & -0.350 & -2.253 & $0.028 *$ \\
\hline Height & 0.357 & 0.112 & 0.494 & -0.951 & $0.002 * *$ \\
\hline Age & N/A & N/A & -0.122 & -0.608 & 0.346 \\
\hline Weight & $\mathrm{N} / \mathrm{A}$ & $\mathrm{N} / \mathrm{A}$ & -0.093 & 3.178 & 0.546 \\
\hline BMI & N/A & $\mathrm{N} / \mathrm{A}$ & -0.067 & 0.530 & 0.598 \\
\hline Working task & N/A & N/A & -0.205 & $-1.47 \mid$ & 0.147 \\
\hline Physical activity level & N/A & N/A & 0.047 & 0.371 & 0.712 \\
\hline \multicolumn{6}{|l|}{5 TSST (sec) } \\
\hline Constant & 4.600 & 1.722 & - & 2.672 & $0.010^{*}$ \\
\hline Age & 0.122 & 0.040 & 0.369 & 3.207 & $0.004 * *$ \\
\hline Gender & N/A & $N / A$ & 0.058 & $0.47 \mathrm{I}$ & 0.640 \\
\hline Weight & N/A & $N / A$ & 0.119 & 0.973 & 0.335 \\
\hline Height & $N / A$ & $N / A$ & 0.225 & 1.798 & 0.077 \\
\hline BMI & $\mathrm{N} / \mathrm{A}$ & N/A & -0.021 & -0.168 & 0.867 \\
\hline Working task & N/A & N/A & -0.234 & -1.950 & 0.056 \\
\hline Physical activity level & N/A & N/A & -0.213 & -1.762 & 0.083 \\
\hline \multicolumn{6}{|l|}{2 MST (steps) } \\
\hline Constant & 123.757 & 12.938 & - & 9.566 & $<0.00 I^{* *}$ \\
\hline Age & -0.829 & 0.302 & -0.339 & -2.747 & $0.008 * *$ \\
\hline Gender & $\mathrm{N} / \mathrm{A}$ & $\mathrm{N} / \mathrm{A}$ & 0.202 & 1.653 & 0.104 \\
\hline Weight & N/A & N/A & -0.057 & -0.455 & 0.651 \\
\hline Height & N/A & N/A & 0.032 & 0.246 & 0.806 \\
\hline BMI & N/A & N/A & -0.118 & -0.941 & 0.351 \\
\hline Working task & N/A & N/A & -0.054 & -0.429 & 0.669 \\
\hline Physical activity level & $\mathrm{N} / \mathrm{A}$ & $\mathrm{N} / \mathrm{A}$ & 0.174 & 1.407 & 0.165 \\
\hline
\end{tabular}

Notes: * Denotes significant difference at $P<0.05$, ** Denotes significant difference at $P<0.01$.

Abbreviations: B, unstandardized coefficients beta; SE, standard error; BMI, body mass index; N/A, not applicable; FRT, functional reach test; 5 TSST, five-time sit to stand test; 2 MST, two-minute step test. 
The second objective was to investigate the effects of demographic data on those functional capacity tests. We found that individual's height and gender have effects on functional reach. A previous study reported that the factors influencing functional reach were height, age, base of support (BOS), and methods of reaching. ${ }^{31}$ This present study corresponds to the previous study regarding height influencing functional reach. However, the previous study investigated growing children with their increasing age associated with increasing height. Therefore, the effect of age cannot apply to the adults. The previous study did not see the effect of gender, but BOS was significantly wider for men than women, ${ }^{31}$ which might explain the difference in gender in this study. Additionally, the methods of reach influenced the values of functional reach, ${ }^{31}$ however, this study used standardized methods of functional reach. Also, the mean height and gender distribution between the two groups in this study were not significantly different.

For the five-time sit to stand and two-minute step tests, only age has an effect on functional capacity, not gender, weight, height, BMI, working task, or physical activity level. Bohannon et $\mathrm{al}^{18}$ found that the five-time sit to stand test had slight correlations with age and BMI. The two-minute step test in this present study corresponds to Rikli and Jones. ${ }^{17}$ 17However, the mean age of the two groups was not significantly different in this study.

One of the limitations of this study was that most of the individuals with CNSLBP had a minimal disability, so the finding of this study may not be widely applicable for individuals with CNSLBP, moderate-to-severe disability. Apart from pain and disability, psychosocial factors would influence functional capacity performance. Further research should include the effect of psychosocial factors on functional capacity evaluation for providing better management to the patients.

\section{Conclusion}

This study investigated the comparison of functional capacity between the individuals with and without CNSLBP. The result found significant differences in five-time sit to stand and two-minute step tests. Of the demographic data, age significantly affects the five-time sit to stand and twominute step tests, while gender and height significantly affect functional reach. This finding suggests that the functional capacity should be evaluated in a clinical setting for a better understanding of CNSLBP conditions.

\section{Protocol Reference}

Protocol Reference: dx.doi.org/10.17504/protocols.io. bfq6jmze.

\section{Acknowledgments}

The authors would like to express the gratitude to all participants in this study, both the patients who came to the Physical Therapy Center, Faculty of Physical Therapy, Mahidol University and healthy individuals who contributed to this study.

\section{Disclosure}

The authors declare no conflicts of interest in this study. This study received no research funding.

\section{References}

1. Bardin L, King P, Maher C. Diagnostic triage for low back pain: a practical approach for primary care. Med J Aust. 2017;206 (6):268-273. doi:10.5694/mja16.00828

2. Maher C, Underwood M, Buchbinder R. Non-specific low back pain. Lancet. 2017;389(10070):736-747. doi:10.1016/S0140-6736(16)30 970-9

3. Rozenberg S. Chronic low back pain: definition and treatment. Rev Prat. 2008;58(3):265-272.

4. Chou R. Low back pain (chronic). Am Fam Phys. 2011;84 (4):437-438.

5. Patrick N, Emanski E, Knaub M. Acute and chronic low back pain. Med Clin North Am. 2014;98(4):777-789. doi:10.1016/j.mcna.20 14.03.005

6. Hartvigsen J, Hancock M, Kongsted A, et al. What low back pain is and why we need to pay attention. Lancet. 2018;391 (10137):2356-2367. doi:10.1016/S0140-6736(18)30480-X

7. Simmonds MJ, Olson SL, Jones S, et al. Psychometric characteristics and clinical usefulness of physical performance tests in patients with low back pain. Spine. 1998;23(22):2412-2421. doi:10.1097/00007 632-199811150-00011

8. Strand L, Moe-Nilssen R, Ljunggren A. Back performance scale for the assessment of mobility related activities in people with back pain. Phys Ther. 2002;82:1213-1223. doi:10.1093/ptj/82.12.1213

9. Pfingsten M, Lueder S, Luedtke K, Petzke F, Hildebrandt J. Significance of physical performance tests for patients with low back pain. Pain Med. 2014;15(7):1211-1221. doi:10.1111/pme.12482

10. Rudy TE, Weiner DK, Lieber SJ, Slaboda J, Boston JR. The impact of chronic low back pain on older adults: a comparative study of patients and controls. Pain. 2007;131(3):293-301. doi:10.1016/j. pain.2007.01.012

11. Oesch P, Meyer K, Jansen B, Kool J. Functional capacity evaluation: performance of patients with chronic non-specific low back pain without Waddell signs. J Occup Rehabil. 2015;25(2):257-266. doi:10.1007/s10926-014-9533-6

12. Sakulsriprasert P, Vachalathiti R, Vongsirinavarat M, Kantasorn J. Cross-cultural adaptation of modified Oswestry low back pain disability questionnaire to Thai and its reliability. J Med Assoc Thai. 2006;89(10):1694-1701.

13. Roy S, De Luca C, Casavant D. Lumbar muscle fatigue and chronic lower back pain. Spine. 1989;14(9):992-1001. doi:10.1097/ 00007632-198909000-00014 
14. Chang W, Lin H, Lai P. Core strength training for patients with chronic low back pain. J Phys Ther Sci. 2015;27(3):619-622. doi:10.1589/jpts.27.619

15. Lamoth C, Meijer O, Daffertshofer A, Wuisman P, Beek P. Effects of chronic low back pain on trunk coordination and back muscle activity during walking: changes in motor control. Eur Spine J. 2006;15 (1):23-40. doi:10.1007/s00586-004-0825-y

16. Duncan PW, Weiner DK, Chandler J, Studenski S. Functional reach: a new clinical measure of balance. J Gerontol. 1990;45(6):M192M197. doi:10.1093/geronj/45.6.M192

17. Rikli RE, Jones CJ. Development and validation of a functional fitness test for community-residing older adults. J Aging Phys Act. 1999;7(2):129-161. doi:10.1123/japa.7.2.129

18. Bohannona R, Shovea M, Barrecab S, Mastersd L, Sigouinc C. Fiverepetition sit-to-stand test performance by community-dwelling adults: a preliminary investigation of times, determinants, and relationship with self-reported physical performance. Isokinet Exerc Sci. 2007;15:77-81. doi:10.3233/IES-2007-0253

19. Jalayondeja C, Jalayondeja W, Vachalathiti R, et al. Cross-cultural adaptation of the compendium of physical activity: thai translation and content validity. J Med Assoc Thai. 2015;98(Suppl 5):S53-S59.

20. Jalayondeja C, Jalayondeja W, Bovonsunthonchai S, Kaewkhuntee W, Bunprajun T. Thai Physical Activity Guideline (TPAG): A Manual of Physical Activity Promotion in Community. 1st ed. Bangkok: Printery-Company Limited; 2015.

21. Duncan PW, Studenski S, Chandler J, Prescott B. Functional reach: predictive validity in a sample of elderly male veterans. J Gerontol. 1992;47(3):M93-M98. doi:10.1093/geronj/47.3.M93

22. Smeets RJ, Wittink H, Hidding A, Knottnerus J. Do patients with chronic low back pain have a lower level of aerobic fitness than healthy controls?: are pain, disability, fear of injury, working status, or level of leisure time activity associated with the difference in aerobic fitness level? Spine. 2006;31(1):90-97. doi:10.1097/01. brs.0000192641.22003.83

23. Langevin H, Sherman K. Pathophysiological model for chronic low back pain integrating connective tissue and nervous system mechanisms. Med Hypotheses. 2006;68(1):74-80. doi:10.1016/j. mehy.2006.06.033
24. Sakulsriprasert P, Vachalathiti R, Kingcha P. Responsiveness of pain, functional capacity tests, and disability level in individuals with chronic nonspecific low back pain. Hong Kong Physiother J. 2020;40(1):11-17. doi:10.1142/S101370252050002X

25. Yiengprugsawan V, Hoy D, Buchbinder R, Bain C, Seubsman S-A, Sleigh AC. Low back pain and limitations of daily living in Asia: longitudinal findings in the Thai cohort study. BMC Musculoskelet Disord. 2017;18(1):19. doi:10.1186/s12891-016-1380-5

26. Simmonds M. Physical function and physical performance in patients with pain: what are the measures and what are do they mean? Pain 1999. 1999.

27. Matheson LN, Leggett S, Mooney V, Schneider K, Mayer J. The contribution of aerobic fitness and back strength to lift capacity. Spine. 2002;27(11):1208-1212. doi:10.1097/00007632-20020601000013

28. Crombez G, Vlaeyen JW, Heuts PH, Lysens R. Pain-related fear is more disabling than pain itself: evidence on the role of pain-related fear in chronic back pain disability. Pain. 1999;80(1-2):329-339. doi:10.1016/S0304-3959(98)00229-2

29. Vlaeyen J, Kole-Snijders AM, Boeren RG, Van Eek H. Fear of movement/(re) injury in chronic low back pain and its relation to behavioral performance. Pain. 1995;62(3):363-372. doi:10.1016/ 0304-3959(94)00279-N

30. Smeets RJ, Van Geel AC, Kester AD, André Knottnerus J. Physical capacity tasks in chronic low back pain: what is the contributing role of cardiovascular capacity, pain and psychological factors? Disabil Rehabil. 2007;29(7):577-586. doi:10.1080/09638280600925829

31. Volkman K, Stergiou N, Stuberg W, Blanke D, Stoner J. Factors affecting functional reach scores in youth with typical development. Pediatr Phys Ther. 2010;21(1):38-44. doi:10.1097/PEP.0b013e318196f68a
Journal of Pain Research

\section{Publish your work in this journal}

The Journal of Pain Research is an international, peer reviewed, open access, online journal that welcomes laboratory and clinical findings in the fields of pain research and the prevention and management of pain. Original research, reviews, symposium reports, hypothesis formation and commentaries are all considered for publication. The manuscript management system is completely online and includes a very quick and fair peer-review system, which is all easy to use. Visit http:// www.dovepress.com/testimonials.php to read real quotes from published authors. 